\title{
Ensayo sobre la cuestión social ${ }^{1}$ \\ Essay on social question
}

\author{
Alfredo Juan Manuel Carballeda*
}

\section{Resumen}

La Cuestión Social se presenta hoy como una forma de interpelación hacia el orden social, económico y cultural impuesto por las formas actuales del Capitalismo. Se expresa a través de la desigualdad social y la exclusión que afecta a grandes sectores de la población en todo el planeta en forma peligrosamente inequitativa. Sobresalen en ella formas singulares de construcción de subjetividad en un contexto mundial donde la desigualdad se enuncia de forma relevante a partir de niveles hasta ahora desconocidos de concentración de la riqueza en porcentajes ínfimos de la población. Por otra parte, en nuestro continente reaparecen nuevas formas del colonialismo, a veces, de manera disimulada a través de importantes construcciones discursivas donde sobresale lo mediático como instrumento apreciable, sumado a nuevas y sofisticadas formas de control social. Estas, poseen diferentes expresiones de orden punitivo que conjugan de manera novedosa diferentes aspectos objetivos y subjetivos.

Palabras clave: Cuestión Social; Desigualdad; Colonialismo; Fragmentación Social; Intervención Social.

\section{Abstract}

Social Question present it now as a way of interpellation to social, economic and cultural order that current Capitalism impose. It express throw-out social inequality and exclusion that affects several population sectors in whole planet in a nastily inequity form.

\footnotetext{
${ }^{1}$ Artículo publicado previamente en la Revista de Trabajo Social Margen No 89. El texto se reproduce con autorización del editor de la Publicación.

${ }^{*}$ Doctor en Trabajo Social. Magister en Trabajo Social. Diplomado Superior en Ciencias Sociales con Orientación en Sociología. Profesor Titular Ordinario. Investigador Categoría 1 (CONEAU). Universidad Nacional de la Plata. La Plata, Argentina. Correo electrónico: alfredocarballeda@gmail.com.

Universidad del Valle. Cali, Colombia. Recibido: 30/07/2018 Aprobado: 06/11/2018 ISSN: 0122-1213 ISSN-e: 2389-993X Doi: 10.25100/prts.v0i27.7271.
} 
They protrude in it, singular forms of subjectivity construction in a global context where inequality is strongly enunciated hitherto unknown levels of wealth concentration in tiny population percentages.

On the other hand, in our continent new forms of colonialism appears, sometimes, in dissimulated way throw-out greate discursive constructions were media excels and new and sophisticated social control instruments appears. This possesses different punitive expressions that conjugated in a novel manner with different objective and subjective aspects.

Keywords: Social Question; Inequality; Colonialism; Social Fragmentation; Social Intervention.

Sumario: 1. Cuestión Social la tensión Integración-desintegración de la sociedad; 2. Cuestión Social y construcción de Subjetividad; 3. Cuestión Social y la justificación de la Desigualdad; 4. Algunas reflexiones acerca de la desigualdad; 5. Cuestión Social, obscenidad y angustia; 6. Cuestión Social y caída de los valores democráticos; 7. Colonización, Cuestión Social, Cuestión Nacional; 8. Algunas conclusiones; 9. Referencias bibliográficas.

El subdesarrollo no es consecuencia de la supervivencia de instituciones arcaicas, de la falta de capitales en las regiones que se han mantenido alejadas del torrente de la historia del mundo, por el contrario, el subdesarrollo ha sido y es aun generado por el mismo proceso histórico que genera también el desarrollo económico del propio capitalismo.

Gunder-Frank, 1963.

La división internacional del trabajo consiste en que unos países se especializan en ganar y otros en perder. Nuestra comarca del mundo, que hoy llamamos América Latina, fue precoz: se especializó en perder desde los remotos tiempos en que los europeos del Renacimiento se abalanzaron a través del mar y le hundieron los dientes en la garganta.

Galeano, 2002. 


\section{Cuestión Social la tensión Integración-Desintegración de la sociedad}

La fragmentación de la sociedad avanza generando nuevos espacios de exclusión y desencanto. Allí, donde hasta hace poco tiempo se construía futuro y esperanza hoy nos gobierna autoritariamente la incertidumbre acompañada por una falta de expectativa impuesta violentamente que agobia y dificulta la integración social. El Neoliberalismo logra una vez más, tal vez en su etapa de mayor virulencia, socavar los cimientos de sociedades que habían comenzado a recorrer caminos de recuperación de su integración perdida de la mano de la perspectiva de derechos. El retroceso hacia lugares y circunstancias que nunca hubiésemos sospechado invade a nuestra región como una enfermedad contagiosa y endémica que parece no detenerse y va generando más y nuevas formas de dolor y padecimiento. En la historia de los últimos doscientos años nunca hubo una diferencia tan marcada entre quienes concentran la riqueza y quienes quedan afuera de las condiciones mínimas de vida.

La pérdida de derechos fragmenta, individualiza, tanto al conflicto como sus posibles formas de resolución. La presión que se impone a la necesidad de seguir perteneciendo es tal, que se construyen formas de naturalización consensuada de la pérdida de derechos que hasta hace poco tiempo eran consideradas irrenunciables. Se desdibuja lentamente la idea básica de los derechos sociales en una suerte de retroceso al siglo XVIII asentado en que cuando una persona pierde un derecho, automáticamente lo pierde toda la sociedad. El enunciado, tal vez más potente de la Revolución Francesa que afirmaba que todos los hombres nacen libres e iguales se desdibuja en los laberintos oscuros de una economía salvaje de mercado, mostrando probablemente la peor etapa del capitalismo a través de su rostro financiero y codicioso.

Al fragmentarse la sociedad, estallan nuevamente las instituciones y los territorios vuelven a tomar las formas de guetos urbanos donde la presencia del Estado se restringe día a día en la esfera de los derechos y se incrementa en lo punitivo. Esa fragmentación construye nuevas formas de subjetividad donde también se multiplica la inseguridad con respecto al Otro, a la sociedad, a la organización de la vida cotidiana. El padecimiento 
recorre caminos complejos que van desde la singularidad, dialogan con lo territorial y se entremezclan con las circunstancias que marcan el sentido de lo macro social.

\section{Cuestión Social y construcción de Subjetividad}

El sentido común y la vida cotidiana se edifican en gran parte a partir de la violencia que forma la concentración de la información. Mientras tanto, el terrorismo de mercado genera nuevos signos en la construcción de subjetividad; en ellos, el temor a perder lo poco que a cada uno le queda genera tensiones y violencia. Vivimos en Sociedades donde se fomenta y exalta el egoísmo, mientras que la meritocracia se propone a sí misma como el único camino posible para escapar de una hecatombe que es producto de niveles nunca vistos de concentración de la riqueza a nivel mundial. Al naturalizarse la pérdida de derechos sociales, subrepticiamente, nuestras sociedades se hacen más injustas y cada vez menos libres. La ecuación donde sencillamente una necesidad se transforma de manera automática en un derecho social no cumplido es olvidada, reprimida, ocultada por los dueños de la comunicación, quedando relegada a espacios cada vez menos visitados en la esfera del sentido común. Así, la pérdida de derechos sociales trae un consecuente impacto en los derechos civiles que queda naturalizada e invisible. La noción de igualdad se separa de la de libertad y olvida premeditadamente la de fraternidad. La vinculación entre mérito y derecho es también una bandera que ostenta el triunfo del neoliberalismo mientras avanza en su batalla cultural conquistando puntos de vista y construyendo sentido común.

La incertidumbre atraviesa y se naturaliza en la vida cotidiana y, el solo pensar en el futuro puede transformarse en malestar, padecimiento, evocación del dolor que se vincula con la frustración. Las sociedades de mercado intentan convencer mediante estrategias publicitarias y comunicacionales la separación y sensación de extrañeza frente al Otro, afirmándose en la ilusión de que es posible sobrevivir individualmente, mejorar sin sociedad, sin cultura, sin historia. Se reproduce el discurso de los manuales y procedimientos que se apoyan en un individualismo 
exaltado, fundamentalista y patético, donde pareciera que se pretende que los restos de los lazos sociales queden simplemente propuestos y enunciados a través de la lógica del costo y el beneficio. En la cultura neoliberal, la libertad individual se enuncia desde un egoísmo que transforma al prójimo en un instrumento, en un medio para un supuesto bienestar hedonista e indefectiblemente efímero, solitario y aislado. Pareciera que cada vez más la vinculación con los otros se desarrolla a través de la violencia cotidiana, política, verbal, física, las peleas entre personas que circulan por las calles, expresan lo que muestran las pantallas de televisión y desde allí multiplican la sensación de espanto frente al Otro. La inseguridad social es una construcción que tiene gran parte de su condición objetiva en la ausencia, en nuestro caso, repentina de un Estado que lentamente estaba intentando acompañar, cuidar cobijar, para mutar de pronto en una especie de monstruo, cada vez más parecido a un Leviatán que desenmascara su faceta más arrogante y represiva.

De esta manera, a partir de las promesas de éxito que exaltan solo el esfuerzo individual y competitivo, el futuro se torna angustiante en un mundo donde la capacidad de consumo muestra el lugar que cada uno posee en nuevas formas de estratificación social, mientras que el Otro es presentado y vivido como alguien que está al acecho esperando el momento para la usurpación de la ilusión de las seguridades conseguidas. El padecimiento se multiplica en una cultura donde desde muchos sectores se acepta y se sabe en forma implícita, silenciosa y con vergüenza. Como así también desde lo explícito y prepotente, que no hay lugar para todos en las sociedades que se construyen teniendo como base a la desigualdad. Sociedades, donde, la angustia se presenta como una construcción permanente o un efecto, porque no premeditado, para disciplinar y generar nuevas formas de control. En ellas se reafirma la construcción de diferentes cadenas causales de desventajas que operan desde las perspectivas de los discursos hegemónicos como producto de déficits personales, individuales, desde la "falta de superación" o la "desmotivación". De esta forma la secuencia que va desde el estereotipo al prejuicio y desde allí a la estigmatización se reproduce y sostiene, no solo como una conjunción entre la justificación y la explicación de lo social, sino como una forma de padecimiento subjetivo que es vivido esencialmente como culpa. 


\section{Cuestión Social y la justificación de la Desigualdad}

La pobreza, los efectos de la desigualdad se tornan vergonzantes, así el padecimiento se inscribe a través de una doble vía: por un lado, la de la necesidad objetiva no cumplida y por otro, la de la situación de habitar en el mundo de los excluidos. La comunicación prácticamente secuestrada por un periodismo que se autodenominó “de guerra", pulverizó la idea de opinión pública y nos demuestra sin pudor cómo la verdad puede ocultarse, negarse, hacer que sea olvidada Así, en esa forma de comunicación que se constituye también como relación social predomina la violencia, la coerción, la presión del más fuerte, logrando operar como control social de la vida cotidiana, el sentido común y la democracia. De este modo, la comunicación además de ser el instrumento preferido en estas sociedades de control, es también control en sí misma, a partir de imperativos, afirmaciones y violencias.

El Otro deja de ser sujeto si está en situación de exclusión social, ingresa a un oscuro espacio de los que están por fuera del ser, se deshumaniza, queda invisibilizado así, reaparecen formas de explicación que sirvieron para justificar desde la "ley" en la conquista y la expoliación, la esclavitud, la desigualdad, la inferioridad.

Ese Otro es precedido por su imaginario y desde allí también se gesta una forma de control dual que opera, por un lado, como un auto disciplinamiento y por otro, se conjuga con la mirada de quienes transitan los espacios de la inclusión, la normalidad o cumplen con las expectativas del mercado.

Pareciera que al estallar el trabajo como forma de organización de la sociedad, se vuelve a los viejos esquemas de sociedades estamentales que se utilizaron para la conquista de nuestro continente donde las desigualdades sociales fueron construidas especialmente desde la noción de raza.

Como una de las explicaciones, en los postulados neoliberales actuales, reaparece una forma de positivismo que se pretende imponer a través de la auto superación, la autoayuda y el voluntarismo individualista, construyéndose así una extraña mezcla entre la condición genética de las personas y su capacidad de incorporar una suerte de voluntad puritana, que opera como una forma de justificación sin pudor de la desigualdad. 
Como signo de la época surge el rechazo al excluido, al pobre, esencialmente a su condición humana. De este modo, al perder su humanidad, la violencia del mercado también llega en lo micro social y, de manera capilar, bajo la forma de violencias que van desde el rechazo y la insensibilización, el insulto, la agresión, y llegando hasta al linchamiento y a los llamados crímenes de odio. Una feroz y espantosa amalgama que integra miedo y rechazo a los desposeídos, los expoliados, los excluidos, es uno de los efectos naturalizados en las sociedades donde el terrorismo de mercado es el gran constructor de subjetividad. Justamente, esta construcción puede ser entendida como un proceso en el cual, desde los discursos de poder se construye la explicación individualizada que busca las causas de lo que ocurre solamente en la esfera de quienes padecen la desigualdad. De este modo, se logra una sugestiva construcción, que posee a veces altos niveles de consenso, donde las víctimas son las primeras culpables de lo que les ocurre y como en los escenarios dominados por psicópatas, estas también se ubican en ese lugar de la culpa. Consecuentemente, la pobreza se construye como amenaza y situación degradante que sirve para justificar todo tipo de violencia que se ejerza sobre quienes la padecen.

Así se justifican las persecuciones a las diferentes víctimas de la desigualdad; los inmigrantes, los campos de concentración para "indocumentados", la discriminación y otras formas de violencia. Mientras tanto, en nuestros barrios y ciudades, se multiplican los comedores comunitarios, el número de familias que vive en las calles, los hogares que van restringiendo silenciosamente sus hábitos hasta llegar a lo alimentario.

Por los barrios más castigados por el neoliberalismo circula un aullido de desesperanza, tan fuerte que no puede ser escuchado, tan potente que genera silencio, pero, también rabia y resistencia en aquellos que logran percibirlo como una fuerza que se instaló para logar la desigualdad. Las miradas tristes del desempleo, de los padres que saben que ya no alcanza para comer, evocan en forma de añoranza, posiblemente como en un sueño, un pasado reciente donde los derechos estaban ahí, como algo natural e insustituible. 


\section{Algunas reflexiones acerca de la desigualdad}

Según los informes de diferentes organismos internacionales, es posible concluir que la riqueza extrema de unos pocos se erige sobre el trabajo esclavo y mal remunerado de la mayoría a nivel mundial. La economía genera confort y buenas condiciones de vida para grupos sociales cada vez más restringidos. El trabajo, prácticamente no remunerado o esclavo de personas apresadas en la pobreza por las políticas económicas del sometimiento, genera una siniestra ecuación donde los beneficios del crecimiento económico van a parar a grupos cada vez más reducidos.

Las grandes corporaciones, el poder financiero internacional, y las personas más ricas aparecen como un factor significativo de esta crisis de desigualdad. Utilizan su poder e influencia para garantizar que las políticas gubernamentales vayan a favor de sus intereses y se sostienen a través de la desolación que genera el endeudamiento de las naciones más pobres del mundo. Así, el $94 \%$ de la riqueza mundial se concentra en los países más ricos. Quienes se les oponen, suelen ser perseguidos, asesinados o acusados de corrupción a través de medios de comunicación concentrados y afines, contando muchas veces con complicidad judicial y de otros políticos. Estas nuevas formas de alteración del orden democrático atraviesan nuestra región, van desde la mentira blindada a través del monopolio de la información, hasta la desestabilización y caída de gobiernos democráticos, pasando por el encarcelamiento de opositores. De esta manera, la contradicción entre igualdad y desigualdad es ocultada, sobresaliendo los discursos que denuncian de manera fatalista a la corrupción dejándose de lado las principales causas de la desigualdad. Desde la descripción de complejos procesos de corrupción que terminan siendo explicados de manera infantil se oculta la violencia del saqueo de nuestros pueblos. Mientras tanto, en el campo de las Ciencias Sociales, surgen múltiples debates acerca de los porcentajes y número de pobres, pero poco se discute acerca de la desigualdad y sus causas económicas y financieras.

El año pasado (2017), se produjo el mayor aumento de la historia conocida y registrada en el número de personas cuyas fortunas superan los mil millones de dólares, con un nuevo "milmillonario" cada dos días. En tan Prospectiva. Revista de Trabajo Social e intervención social No. 27, enero-junio 2019: pp. 13-28 (c) (i) () () 
solo 12 meses, la riqueza de esta élite ha aumentado en 762.000 millones de dólares. Este incremento podría haber terminado con la pobreza extrema en el mundo hasta siete veces y generado niveles relevantes de igualdad social. Pero, el $82 \%$ de la riqueza generada fue a parar a manos del 1\% más rico, mientras el $50 \%$ más pobre de la población mundial obtuvo el $0 \%{ }^{2}$

A través de la coacción y otras formas de presión política, económica, mediática y militar el poder financiero internacional le asigna a las economías de los países que paulatinamente fue empobreciendo, especialmente en las últimas décadas, el papel de productores y exportadores de materias primas y productos agrícolas. Pero también, los ubica en el lugar de consumidores y consecuentemente de importadores de productos industriales y tecnológicamente que los países centrales producen gracias a los insumos que saquean. Desde la política, los países más poderosos generan una presión permanente para que nuestros países se endeuden, generando de esta manera una doble forma de sometimiento. La toma de deuda por parte de los países periféricos se transforma en otra forma de obtención de beneficios para los países centrales que de esta forma van sosteniendo la concentración y estabilidad de su economía.

\section{Cuestión Social, obscenidad y angustia}

Por otro, lado, y de manera peligrosamente naturalizada, la concentración de la riqueza se transforma en una ostentación obscena, donde los beneficiarios de un modelo económico que excluye y genera dolor muestran sus fortunas, sus bienes exhibiéndolos de manera impúdica, así, la pompa, el alarde, la suntuosidad, se tornan obscenos y son mostrados como una provocación perversa. También es hediondo y espantoso que, como respuesta a la desigualdad reaparezca una forma denigrante de la caridad que es utilizada como marketing comercial o, simple estrategia de evasión de impuestos. La obscenidad en nuestras sociedades se construye en definitiva a través de que todo, incluidos los cuerpos, se fue transformando lentamente en mercancía.

${ }^{2}$ https://www.oxfam.org/es/iguales/cinco-datos-escandalosos-sobre-la-desigualdad-extremaglobal-y-como-combatirla.

Prospectiva. Revista de Trabajo Social e intervención social No. 27, enero-junio 2019: pp. 13-28 
Así, la identidad, la pertenencia, la socialización, tienen el precio que decide el mercado y son mercancías negociables. Desde allí se construye una nueva forma de integración social que excluye o incluye premeditadamente a través del poder económico de cada uno. Por otra parte, la sensación de no pertenecer a un todo social genera la aparición de derechos subjetivos, donde pareciera que cada individuo construye desde su propia perspectiva su esfera de derechos y obligaciones, donde lo que sobresale es la preponderancia de "uno mismo".

La noción de responsabilidad en la cultura actual poco tiene que ver con una idea de sociedad como algo que integra, sostiene y da sentido, identidad y pertenencia. El neoliberalismo construye una forma de subjetividad que es atravesada por la angustia. Como en una ciudad permanentemente bombardeada, el miedo, el temor ante lo impreciso, la posibilidad de presencia de circunstancias amenazantes de todo tipo, trae una espera que anuncia lo irremediable del próximo golpe y multiplica la desesperanza. Así actúa el terrorismo de mercado, amenazando con múltiples formas de inseguridad. El temor a la muerte social, a caer en los oscuros espacios de la exclusión se relaciona con la precarización del trabajo, las violencias cotidianas, la amenaza permanente de agresión física o psíquica, la inseguridad, así es una construcción social, un producto del clima de época y de las estrategias de comunicación. Una inseguridad que se expande en forma geométrica y genera que la certeza pase solamente por la esfera de lo individual. Una inseguridad que genera fundamentalmente soledad. Una conjunción siniestra de angustia e incertidumbre que permite más eficientes formas de control y disciplinamiento social.

\section{Cuestión Social y caída de los valores democráticos}

El neoliberalismo condiciona, encierra y si lo necesita, arrasa con la democracia. De esta forma, la sociedad bajo ese sistema económico, deja de concebirse como un todo conformado por ciudadanos soberanos para convertirse en un conjunto de consumidores donde, los derechos dependen de la capacidad de compra u ahorro de cada uno de sus integrantes. 
Por otro lado, la caída de los valores democráticos hace que se relativice la Justicia, las instituciones o las prácticas que se desarrollan en ellas. Estas se encuentran nuevamente deslegitimadas al no poder cumplir con sus mandatos fundacionales. La separación de las nociones de Libertad, Igualdad y Fraternidad, hacen que cada una de ellas compita con la otra y dejen de potenciarse. Así, la Igualdad de unos puede ser vista como producto de la pérdida de libertad de otros, mientras que la noción de fraternidad, asociada a la de Pueblo y Nación pareciera estar censurada u olvidada.

La crisis de los espacios de socialización ha retornado con vehemencia: la familia, el barrio, la escuela se encuentran reiteradamente cambiando de sentido y también atraviesan nuevamente por una fuerte crisis de legitimidad. La desigualdad torna violentas a las sociedades en muchísimos aspectos pero, solo se ponen en evidencia y son percibidos subjetivamente como importantes aquellos que implican algún atentado contra la propiedad privada. Las violencias que llevan adelante los que detentan el poder a través de la degradación de la economía, generación de desempleo y concentración de la riqueza, raramente se registran como problema que afecte la integridad individual.

Ante la conflictividad creciente, las nuevas expresiones de la biopolítica intentan desde una forma remozada del positivismo la psiquiatrización del conflicto, nominando el padecimiento en clave de nuevas y viejas clasificaciones psicopatológicas que colateralmente también se utilizan para la justificación de la inferioridad genética de quien está en situación de desigualdad.

La estrategia neoliberal hoy, pareciera que va más allá del control de los cuerpos, muchas veces no necesita del encierro, genera cárceles que cada uno de nosotros construye y habita para sentirse seguro y separado de los otros; así, avanza sin pausa en la construcción de subjetividad y la enunciación de los problemas sociales desde lo individual. La vida cotidiana, en estos escenarios, sufre una suerte de psicologización donde, los condicionantes de lo que ocurre se restringen a la esfera de lo íntimo y solitario. En la actualidad, el poder colonial, el poder que nos sujeta retorna de manera más evidente y sofisticada como biopoder y construcción 
subjetiva, intentando disciplinar desde la subjetividad, los cuerpos y el lenguaje.

La represión es justificada como necesaria para mantener un supuesto orden donde los que tienen los derechos y las libertades de las ciudadanías plenas son cada vez menos. Los fantasmas de la Dictadura Militar, ya cohabitan con nosotros y volvemos a ver ahora como reaparecen disfrazados de una especie "necesidad de seguridad" que reflotó el fascismo latente de una parte de nuestras sociedades. Se justifica que las policías actúen por fuera o en el límite de la ley en nombre de restablecer una seguridad que el mismo modelo económico y social de manera cada vez más autoritaria genera. De esta forma la Democracia se restringe en las libertades individuales castigando también a la sociedad como un todo.

Así, la cuestión social se hace más compleja y dolorosa cuando la sociedad es fragmentada, cuando lo social se desvaloriza desde diferentes discursos y perspectivas, cuando la desigualdad social es tan evidente que deja de verse. En un nuevo período histórico donde lo económico condiciona a lo político, lo social y lo cultural.

Por otra parte como todo Poder, la construcción neoliberal de éste, genera Resistencia y desde allí, cada acto de reflexión se transforma en este aspecto también en una manera de resistir, de espera analítica y estratégica, de necesidad de los otros, de lo colectivo, de lo social.

\section{Colonización, Cuestión Social, Cuestión Nacional}

A partir de la conquista de América surge la modernidad, su sustento es el colonialismo que viene operando desde hace más de quinientos años en la forma de construcción de diferentes formas de dominación que pasan por lo económico, lo cultural y lo subjetivo. El colonialismo también permitió y facilitó la universalización de las relaciones mercantiles, la generación de sociedades que justificaron los tipos de individualización que fueron y le son funcionales. También generó los condicionantes de distintas formas de construcción de subjetividad intentando elaborar y establecer ontologías que se pretenden universales. Gracias al sometimiento colonial de América se constituyó y se sigue construyendo la universalización del 
saqueo que proponen las formas actuales del capitalismo, donde tal vez, las mayores victorias fueron conseguidas en los momentos en que los esclavos quisieron parecerse a los amos.

El sujeto en América Latina se construye a partir de su condición de colonizado, tanto desde lo material como lo cultural. Es la expresión de una subjetividad producida desde prácticas que dominan, condicionan, pero también fundamentalmente generan resistencia. Esa subjetividad es el resultado de un proceso socio histórico que se inicia con la conquista y lo atraviesa más allá de su condición social, étnica, económica o cultural. El colonialismo, de esta manera, es como un fantasma que se presenta en el momento menos esperado, opera y construye formas de hacer, pensar, comprender y explicar.

En tanto sujetos americanos, nuestra subjetividad es constituida en complejos juegos de interrelación con la otredad que también se presenta situada y enredada a partir del devenir que constituyen los condicionamientos que impone el colonialismo y las diferentes formas de dominación que lo acompañaron desde la conquista.

El colonialismo tradicional se expresaba a través de ejércitos que entraban a países, regiones, espacios estratégicos que eran adicionados para obtener diferentes tipos de recursos, imponer un sistema de dominación político y económico por medio del ejercicio de la fuerza y la complicidad de aliados internos. En la actualidad, el colonialismo posee componentes mediáticos, financieros y militares. Al igual que en su etapa anterior, desarrolla diferentes empresas o financieras que se apropian de tierras, recursos monetarios, naturales que son saqueados y llevados nuevamente a las metrópolis y allí generan a través de la imposición financiera fuertes lazos de sujeción desde lo económico, lo político y lo cultural. Así...

El colonialismo es todo aquel modo de dominación basado en la degradación ontológica de las poblaciones dominadas por razones etnorraciales. A las poblaciones y a los cuerpos racializados no se les reconoce la misma dignidad humana que se atribuye a quienes los dominan. Son poblaciones y cuerpos que, a pesar de todas las declaraciones universales de los derechos humanos, son existencialmente considerados como subhumanos, seres inferiores en la escala del 
ser. Sus vidas tienen poco valor para quien los oprime, siendo, por tanto, fácilmente desechables... ${ }^{3}$

La colonización cultural hace que la subjetividad surja en espacios dificultosos para la construcción de autonomía. Quizás, el análisis, estudio y exposición de sus procedimientos, donde sobresale la potencialidad del funcionamiento del discurso colonial para generar subjetividad sea un campo político necesario a trabajar. Así, el discurso colonial por un lado deshumaniza al colonizado pero, por otro genera una forma de deseo que a veces es la única mediación con el mundo de los colonizados (Fanon, 1973). El sujeto deja de ser esclavo cuando tiene una utopía, un lugar a donde ir, una sociedad a construir una condición humana a recuperar, cuando vuelve a tener la fortaleza política de su capacidad de mediar con la cultura del colonizador desde un lugar de poder generado en su propia pertenencia, identidad, historia y anclaje en lo colectivo.

\section{Algunas conclusiones}

Es posible pensar que el lugar de las Ciencias Sociales hoy más que nunca trasciende la descripción de los hechos y a la denuncia de éstos, necesitando generar formas de aplicación, de hacer que logren estar allí donde el dolor se hace cuerpo y palabra. De este modo el Trabajo Social se hace necesidad, especialmente desde su capacidad de hacer ver, de generar acontecimiento.

El conocimiento acerca de la cuestión social en nuestra región puede dar cuenta de una serie de elementos que no solo pueden ser útiles para describir las deformaciones del capitalismo actual, sino también para explicarlas y entender por qué se reproducen. Las particularidades del capitalismo dependiente no son resultado de su incapacidad de crecer o de permanecer en el estancamiento, sino, al contrario, del crecimiento de la reproducción del capital. ${ }^{4}$

3 https://www.pagina12.com.ar/105534-el-colonialismo-insidioso. Boaventura de Sousa Santos. El Colonialismo insidioso.

${ }^{4} \mathrm{http}$ ://www.ungs.edu.ar/noticiasungs/?portfolio=la-teoria-de-la-dependencia-hoy. 
Buscando formas de intervención en lo social que fundamentalmente logren la visibilidad del Otro, construyendo formas de re encuentro, colonizando prácticas y saberes que nos permitan pensar desde América y hagan salir a nuestras sociedades de la dominación que las pone en el lugar de la imposibilidad, de la impotencia. Facilitando así la reconstrucción de las subjetividades devastadas en las diferentes crisis, generando prácticas situadas e implicadas que construyen una diferente forma de mirar, de comprender, de explicar.

Son momentos difíciles, complejos, oscuros. Tiempos donde la impotencia, la bronca, el desencanto nos invaden desde una especie de melancolía y nostalgia ligadas a un pasado reciente y esperanzador. Instantes que se transforman en infinito donde nos es difícil entender a través de la razón. Tal vez, sea el camino de la pasión, de los sentimientos, de la épica, lo que nuevamente nos sirva para la explicación de los acontecimientos. Sencillamente viendo, sintiendo, observando donde se festeja lo que nos está ocurriendo y donde la tristeza se expande.

Los procesos de nuestro continente son épicos y heroicos, lentos, construidos desde un sinnúmero de condiciones de sometimiento que nos llegan de quienes nos venden desde adentro y quienes permanentemente nos saquean desde fuera. Pero, la historia nos va mostrando cómo superamos los escollos, cómo cumplimos con el destino cargando de sentido luchas donde siempre peleamos en inferioridad de condiciones, batallas que ganamos y perdemos.

Hoy, en los tiempos donde la oscuridad de la derrota atraviesa prácticamente todo el continente, es seguro que están empezando a brotar muy despacio, y de manera estratégica, nuevas primaveras que nos llenarán nuevamente de proyecto. Tiempos donde la perplejidad y el agobio se transforman en el combustible de la lucha y resistencia. Pero también en la certeza de que los sueños se alejan rápidamente del espectáculo del marketing individual para apresuradamente resguardarse en lo colectivo, quizás, solo para seguir siendo.

Tal vez esa sea la magia que tenemos en América y que estamos aprendiendo con mucho dolor a utilizar, transformando la adversidad en victoria en forma colectiva, hermanada y solidaria. 


\section{Referencias bibliográficas}

Fanon, F. (1973). Piel negra, Máscaras blancas. Buenos Aires: Editorial Abraxas.

Galeano, E. (2002). Las venas abiertas de América Latina. Buenos Aires: Editorial Siglo veintiuno editores.

Gunder-Frank. A. (1963). América Latina: Subdesarrollo o Revolución. México: Editorial ERA.

Cómo citar:

Carballeda, A. (2019). Ensayo sobre la cuestión social. Prospectiva. Revista de Trabajo Social e intervención social, (27), 13-28. Doi: 10.25100/prts.v0i27.7271. 